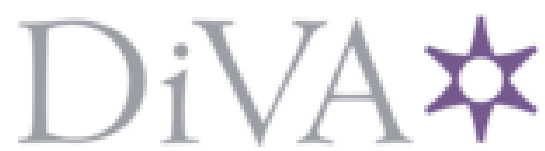

http://www.diva-portal.org

This is the published version of a paper presented at EVOLANG10.

Citation for the original published paper:

Johansson, S. (2014)

Did language evolve incommunicado?.

In: Cartmill et al (ed.), The Evolution of Language: Proceedings of the 10th International

Conference (EVOLANG10) Singapore: World Scientific

N.B. When citing this work, cite the original published paper.

Permanent link to this version:

http://urn.kb.se/resolve?urn=urn:nbn:se:du-26391 


\title{
DID LANGUAGE EVOLVE INCOMMUNICADO?
}

\author{
SVERKER JOHANSSON \\ School of Education and Communication, University of Jönköping, Box 1026, \\ Jönköping, SE-551 11, Sweden \\ lsj@hlk.hj.se
}

\begin{abstract}
It is commonly assumed in evolutionary linguistics that language evolved for communication. But much recent work in biolinguistics, e.g. Chomsky (2010), proposes instead that language evolved for purely internal use, as a cognitive tool, with no externalization until at a later stage in language evolution.

How well supported is really our general assumption of communicative language origins? Does it make sense to have instead an early stage with internal language only? I will review the arguments invoked in favor of the incommunicado hypothesis, and critically evaluate their strength.
\end{abstract}

\section{Introduction}

When investigating the evolutionary origins of any feature of an organism, one pertinent question is whether it is an adaptation, and if so, what it is an adaptation for. What provided the adaptive advantage that originally made the feature spread in the population (cf. Tinbergen, 1963), what was its function?

In most work on evolutionary linguistics, it is generally assumed that language evolved for communicative purposes (Pinker, 1998; Jackendoff, 2002; Johansson, 2005; Dessalles, 2009; Givón, 2009; Bickerton, 2009, among many others). The vast majority of specific hypotheses proposed for language evolution likewise postulate a selective advantage that has something to do with communication. What distinguishes these hypotheses is mainly what the communication is about, and why and for whom the communication provides an evolutionary benefit.

But there has long been a minority of scholars who propose that the original function of language lay in some other area than communication (Jerison, 1973; Chomsky, 2002; Newmeyer, 2004; Turner, 2004; Mirolli \& Parisi, 2006; Lupyan, 2008). In recent years, a specific non-communicative hypothesis, growing out of the minimalist program (Chomsky, 1995), has gained a fair amount of supporters among those who study language origins under the label 'biolinguistics' (Chomsky, 2010; Piattelli-Palmarini, 2010; Berwick \& Chomsky, 2011; Berwick, 2011; Boeckx, 2013).

According to this hypothesis, language was originally a cognitive tool: “...language is not properly regarded as a system of communication. It is a system for 
expressing thought, ..." (Chomsky, 2002, p 76), "If so, then it appears that language evolved, and is designed, primarily as an instrument of thought." (Chomsky, 2007, p 22). For some non-negligible period of time during language evolution, language was not externalized at all, nor linearized, but was instead used purely inside the head with no connection to sensorimotor systems (Chomsky, 2010; Hauser, 2011b; Boeckx, 2013).

The use of language for communication is not only viewed as evolutionarily secondary, it is also downgraded in importance. Chomsky argues that "The use of language for communication might turn out to be a kind of epiphenomenon." (2002, p 107). Language evolution was incommunicado.

Communication between proponents of communicative and noncommunicative language origins hypotheses has not always been fruitful and constructive; the debate sometimes looks like an illustraton of the incommensurability of paradigms (cf. Kuhn, 1962). My purpose in this work is to attempt to bridge the incommensurability gap, coming from the communicative side and looking at the arguments of the other side, critically but without dismissing them out of hand.

I will first summarize briefly the arguments proposed in favor of the incommunicado hypothesis, after which I will go on to review the various problems and weaknesses of the hypothesis.

\section{Arguments for non-communicative language origins}

Indubitably language is an important cognitive tool for humans today, and our "inner speech" constitutes a major fraction of actual language usage (Chomsky, 2002), but that in itself does not prove that cognition was its original raison d'être; language is likewise an important communicative tool today. The arguments provided in favor of the incommunicado hypothesis are instead as follows:

- Asymmetry of the interfaces. This argument is strongly rooted in the minimalist paradigm, with the core of language regarded as a computational module forming a perfect connection between the conceptual-intentional (C-I) and sensorimotor (SM) interfaces. As argued by e.g. Chomsky (2010), the existence of manifest imperfections at the SM side entails that the locus of perfection must rather be at the C-I side, implying that language was optimized for the C-I-interface first, with SM tacked on afterwards.

- Language badly designed for communication. This argument is closely related to the preceding one, but proceeds from a different starting point. It is argued by e.g. Berwick (2011) that language has numerous universal features that are difficult to explain if language evolved for communication, from which it is concluded that language didn't evolve for communication.

- Modality-independence of language. As is well known, language works perfectly fine in a variety of modalities, notably both spoken and signed. 
Chomsky (2010) invokes this as further evidence of the asymmetry of the interfaces; apparently language can work with several different externalization modules (different SM interfaces?), which likewise is taken to imply that externalization was a secondary development, retrofitted to an existing internal language.

- Lack of reference relation in language. As argued by Chomsky (2010): “... there appears to be no reference in human language and thought ... Referring is an action, and the internal symbols that are used to refer do not pick out mind-independent objects. (p. 57) The symbols of speech, in contrast with animal calls, are only internally connected, without external reference, something which makes more sense if externalization and communication are secondary aspects of language.

- The sudden emergence of language. Logically, there is no necessary connection between incommunicado and sudden origins. Nevertheless, much of the incommunicado literature proposes a saltational origin for language, with a single critical mutation providing syntax: "The simplest assumption, ..., is that the generative procedure emerged suddenly as the result of a minor mutation." (Berwick \& Chomsky, 2011, p. 29), with similar statements also found in e.g. Piattelli-Palmarini (2010) and Chomsky (2005, 2010); cf. the "hopeful monsters" of Goldschmidt (1940). Piattelli-Palmarini (2010) is also strongly anti-adaptationist and anti-selectionist, in contrast with Chomsky (2010) who provides a selectional scenario for the spread of the putative single mutation. The saltational hypothesis is connected with and supported by the belief that language is of sudden recent origin, perhaps 50,000-100,000 years ago (e.g. Berwick \& Chomsky, 2011).

\section{Reasons why incommunicado is implausible}

Here I will first provide comments on and counterarguments to the arguments reviewed in the previous sections. After that I will proceed with other considerations that are problematic for the incommunicado hypothesis.

- Asymmetry of the interfaces. This argument carries weight only within the minimalist paradigm, and is powerless unless it is assumed that the minimalist thesis (Chomsky, 2000) is basically true, both in that the picture of language as a bridge between interfaces is correct, and in that language is optimal. Here the incommensurability problem is manifest; from a perspective outside minimalism, the imperfections on the SM side, that Chomsky (2010) concedes, could rather be interpreted as falsifying the postulated perfection of language, in which case Chomsky's asymmetry argument would be downgraded to just an ad hoc effort to save his thesis. 
- Language badly designed for communication. The strength of this argument likewise depends on the underlying assumption that language is optimal in some sense, well designed for whatever it is designed for. But this assumption is not self-evidently true; imperfections are a common outcome in evolutionary tinkering (cf. Jacob, 1977). The eye, for example, has obviously evolved for vision, but the reverse orientation of the retina and the resulting blind spot is just as obviously bad design for vision. Furthermore, do we understand the whole system of human communication well enough to be sure that the quirks invoked by Berwick (2011) are really badly designed for communication? Berwick mainly talks about parsing difficulties, but that is only one aspect of communication; language as a communicative tool is presumably some kind of compromise between the interests of the speaker and the interests of the hearer, and parsing difficulties for the hearer might be compensated by corresponding advantages for the speaker.

- Modality-independence of language. This is indeed a very interesting feature of our language faculty, which any serious hypothesis of language origins must account for. But the account of Chomsky (2010) is not the only possibility. Notably, the various hypotheses postulating an early gestural stage in language evolution (e.g. Corballis, 2002) account for it in a totally different way. Polymodal hypotheses might likewise provide a natural explanation for modality-independent language evolution in a social communicative context (Dor, Knight \& Lewis, in press).

- Lack of reference relation in language. Again, Chomsky (2010) correctly identifies an interesting and unusual feature of our language faculty, in the very indirect ways that our symbols connect with any kind of external reality. But the lack of direct reference is a problem also in the incommunicado scenario; if the putative language of thought is to be used for thinking "about" anything useful, external reference remains an issue. The incommunicado hypothesis does not solve this problem; it would still be the case that " $t$ ] hese properties... have to be accounted for somehow in the study of their evolution. How, no one has any idea. (Chomsky, 2010, p. 58).

- The sudden emergence of language. Saltational hypotheses have a welldeserved poor reputation in evolutionary biology (Kinsella, 2009; Iordansky, 2006; Futuyma, 1998; Cojocaru, 2009), and recent developments in evo-devo have not done much to change that (Gardner, 2013), contra the claims of Piattelli-Palmarini (2010) and Berwick (2011). Having a single large-effect mutation lead to something that is viable and perhaps even useful is not common, but does happen occasionally, due to robust developmental constraints and modular architecture. But having it lead to something that is both totally novel, and optimal or perfect in any reasonable sense, 
is unlikely in the extreme (Kinsella, 2009). Positing a saltational origin for language effectively amounts to positing sheer dumb luck as an explanation, which is far from the principled explanations sought by Chomsky (2005). The belief that language popped up suddenly and recently less than 100,000 years ago is not supported by recent results from archeology and genetics. Instead proxies for language, including externalization, appear gradually and piecemeal over a long period, in both early Homo sapiens and Neanderthals (Johansson, 2011, 2013; Dediu \& Levinson, 2013).

In summary, none of the arguments invoked in favor of the incommunicado hypothesis is compelling. Furthermore, the notion of an incommunicado period in language evolution has a number of other problems as well. For one thing, it does not pass the "chimp test" (Bickerton, 2008); the selective advantage described by Chomsky (2010) for incommunicado language would be just as applicable to chimps as to (proto-)humans, so why don't chimps have it as well? ${ }^{\mathrm{a}}$

If language is primarily and originally a cognitive tool, it is odd that so much of the language machinery in our head is geared towards connecting with the sensorimotor interface, and that so much of the structure of language, notably the enforced seriality of spoken language, is likewise shaped by the demands of the communication channel. Even more odd is the fact that when we do use language as a cognitive tool, we use it in the form of 'inner speech', an apparent internalized form of the externalization of language; this makes more sense with primary externalization later adopted for internal use.

Language acquisition is also problematic. Hauser (2011b) correctly notes that such a non-externalized language could never be transmitted, any "vocabulary" developed by one individual would die with that individual. Hauser then goes on to say that this supports a long incommunicado period in language evolution - but I would argue the opposite; in the putative incommunicado period, it is not clear how language could ever be acquired in ontogeny, given how heavily language acquisition depends on external input. Even though the poverty of the stimulus for language acquisition is notorious, acquisition totally fails without any stimulus at all; cf. the case of Genie (Curtiss, 1977). In the putative incommunicado stage, how did language acquisition ever get off the ground in any individual?

Concerning the neural organisation of language, the incommunicado hypothesis would predict close connections and non-dissociability between cognition and core syntax in the brain. The rather sparse results available from studies examining this issue are mixed. Monti, Parsons, and Osherson (2009) find dissociation between language and logic in the brain, whereas Baldo et al (2010) find that relational reasoning is not separate from language, and Baldo et al (2005) that complex problem solving is impaired both in aphasia patients and in healthy subjects attending to a verbal distractor task.

\footnotetext{
${ }^{\text {a }}$ Or perhaps they do? Without externalization, it is hard to prove that they don't.
} 
Broca's aphasia (Broca, 1861) is noteworthy in that syntax is severely impaired, but other cognitive functions are often largely spared - unlike many other aphasics, Broca patients typically retain their previous non-verbal IQ (Grodzinsky, 2000). If there is any aphasia where core syntax is damaged, it is Broca's. But if core syntax were vital for cognition and conceptual thought, Broca's aphasia would entail severely impaired cognition.

The evidence from empirical data on cognition in pre-linguistic infants and non-linguistic animals likewise indicate that language is not a prerequisite for complex cognition or conceptual reasoning (Fitch, 2009; Hauser, 2011a), and that cognitive representation predates language in both ontogeny and phylogeny (Givón, 2009).

\section{Conclusions}

There is no compelling evidence in favor of the incommunicado hypothesis, at least not outside the minimalist paradigm, and a number of issues, notably language acquisition, are highly problematic. Within the minimalist paradigm, the conjunction of the assumption of perfect language and the manifest imperfection of language externalization do provide some incentive to downgrade the importance of externalization and postulate that language was perfected without externalization. But even within that context, the incommunicado hypothesis would appear to create more problems than it solves.

But the failure of the incommunicado hypothesis does not in itself prove that language evolved for communication. The arguments for and against the various communicative hypotheses need to be evaluated on their own merits.

\section{References}

Baldo et al. (2005). Is problem solving dependent on language? Brain \& Lang 92:240-250.

Baldo et al. (2010). Is relational reasoning dependent on language? a voxel-based lesion symptom mapping study. Brain \& Lang 113:59-64.

Berwick, R. C. (2011). Syntax facit saltum redux: Biolinguistics and the leap to syntax. In A. M. D. Sciullo \& C. Boeckx (Eds.), The biolinguistic enterprise. new perspectives on the evolution and nature of the human language faculty. Oxford: Oxford University Press.

Berwick, R. C., \& Chomsky, N. (2011). The biolinguistic program: The current state of its development. In A. M. D. Sciullo \& C. Boeckx (Eds.), The biolinguistic enterprise. new perspectives on the evolution and nature of the human language faculty. Oxford: Oxford University Press.

Bickerton, D. (2008). Two neglected factors in language evolution. In A. D. M. Smith, K. Smith, \& R. Ferrer i Cancho (Eds.), Evolution of language - evolang7. World scientific.

Bickerton, D. (2009). Adam's tongue. New York: Hill \& Wang.

Boeckx, C. (2013). Lexicon, syntax, and grammar: Biolinguistic concerns. Presented at Congrès International des Linguistes, Genève, 21-27 July. 
Broca, P. (1861). Perte de la parole, ramollissement chronique et destruction partielle du lobe anterieure gauche du cerveau. Bulletins de la Societé d'Anthropologie de Paris $2: 235-238$.

Chomsky, N. (1995). The minimalist program. Cambridge: MIT Press.

Chomsky, N. (2000). Minimalist inquiries: the framework. In R. Martin, D. Michaels, \& J. Uriagereka (Eds.), Step by step: Essays on minimalist syntax in honor of howard lasnik (p. 89-155). Cambridge, MA: MIT Press.

Chomsky, N. (2002). On nature and language. Cambridge University Press.

Chomsky, N. (2005). Three factors in language design. Ling Inquiry 36:1-22.

Chomsky, N. (2007). Of minds and language. Biolinguistics 1:9-27.

Chomsky, N. (2010). Some simple evo devo theses: how true might they be for language? In R. K. Larson, V. Déprez, \& H. Yamakido (Eds.), The evolution of human language. biolinguistic perspectives. Cambridge University Press.

Cojocaru, I. (2009). The revolutionary transition from essentialist to populationary thinking in biology. Analele Ştiinţifice ale Universităţii Al. I. Cuza Iaşi, s. Biologie animală, Tom LV.

Corballis, M. C. (2002). From hand to mouth: the origins of language. Princeton: Princeton University Press.

Curtiss, S. (1977). Genie : a psycholinguistic study of a modern-day "wild child". New York: Academic Press.

Dediu, D., \& Levinson, S. C. (2013). On the antiquity of language: the reinterpretation of neandertal linguistic capacities and its consequences. Frontiers in Psychology 4(397), 1-17, doi:10.3389/fpsyg.2013.00397.

Dessalles, J.-L. (2009). Why we talk. Oxford University Press.

Dor, Knight \& Lewis. (in press). The social origins of language: Early society, communication and polymodality. Oxford: Oxford University Press.

Fitch, W. T. (2009). Prolegomena to a future science of biolinguistics. Biolinguistics 3.4:283-320.

Futuyma, D. J. (1998). Evolutionary biology, 3rd ed. Sunderland: Sinauer.

Gardner, A. (2013). Darwinism, not mutuationism, explains the design of organisms. Progress in Biophysics and Molecular Biology 111:97-98.

Givón, T. (2009). The adaptive approach to grammar. In D. Bickerton \& E. Szathmary (Eds.), Biological foundations and origin of syntax. MIT Press.

Goldschmidt, R. (1940). The material basis of evolution. New Haven: Yale University Press.

Grodzinsky, Y. (2000). The neurology of syntax: language use without broca's area. Behav \& Brain Sci 23(1):1-21.

Hauser, M. D. (2011a). Evolingo: The nature of the language faculty. In Piattelli-Palmarini, Salaburu, \& Uriagereka (Eds.), Of minds and language. a dialogue with noam chomsky in the basque country. Oxford: Oxford University Press.

Hauser, M. D. (2011b). The illusion of biological variation: a minimalist approach to the mind. In Piattelli-Palmarini, Salaburu, \& Uriagereka (Eds.), Of minds and language. a dialogue with noam chomsky in the basque country. Oxford: Oxford University Press.

Iordansky, N. N. (2006). The problem of the evolutionary saltations. Zhurnal Obshchei Biologii 67(4):256-267. 
Jackendoff, R. (2002). Foundations of language. brain, meaning, grammar, evolution. Oxford: Oxford University Press.

Jacob, F. (1977). Evolution and tinkering. Science 196:1161-1166.

Jerison, H. J. (1973). Evolution of the brain and intelligence. New York: Academic Press.

Johansson, S. (2005). Origins of language - constraints on hypotheses. Amsterdam: Benjamins.

Johansson, S. (2011). Constraining the time when language evolved. Linguistic and Philosophical Investigations 10:45-59.

Johansson, S. (2013). The talking neanderthals: What do fossils, genetics and archeology say? Biolinguistics 7:35-74

Kinsella, A. R. (2009). Language evolution and syntactic theory. Cambridge University Press.

Kuhn, T. S. (1962). The structure of scientific revolutions. Chicago: University of Chicago Press.

Lupyan, G. (2008). Extracommunicative functions of language: verbal interference causes categorization impairments. In A. D. M. Smith, K. Smith, \& R. Ferrer i Cancho (Eds.), Evolution of language - evolang7. World scientific.

Mirolli, M., \& Parisi, D. (2006). Talking to oneself as a selective pressure for the emergence of langu. In A. Cangelosi, A. D. M. Smith, \& K. Smith (Eds.), The evolution of language. World scientific.

Monti, Parsons, \& Osherson. (2009). The boundaries of language and thought in deductive inference. Proc Nat Acad Sci 106:12554-12559.

Newmeyer, F. J. (2004). Cognitive and functional factors in the evolution of grammar. In P. Hackney (Ed.), Evolution of language: Fifth international conference, leipzig. http://www.ling.ed.ac.uk/evolang/2004/evolang5.pdf.

Piattelli-Palmarini, M. (2010). What is language, that it may have evolved, and what is evolution, that it may apply to language. In R. K. Larson, V. Déprez, \& H. Yamakido (Eds.), The evolution of human language. biolinguistic perspectives. Cambridge University Press.

Pinker, S. (1998). The evolution of the human language faculty. In N. G. Jablonski \& L. C. Aiello (Eds.), The origin and diversification of language. San Francisco: California Academy of Sciences.

Tinbergen, N. (1963). On aims and methods in ethology. Zeitschrift für Tierpsychologie 20:410433.

Turner, H. (2004). The appearance of design in grammatical universals as evidence of adaptation for non-communicative functions. In P. Hackney (Ed.), Evolution of language: Fifth international conference, leipzig. http://www.ling.ed.ac.uk/evolang/2004/evolang5.pdf. 